\title{
Scarless Wound Healing: Looking for a Single Remedy With Multiple
}

\section{Targets}

\author{
Samila Farokhimanesh, ${ }^{1}$ Mohammad Ali Nilforoushzade, ${ }^{2}$ Nahid Nikkhah, ${ }^{2}$ Ali Komeili, ${ }^{3}$ and Mehrak \\ Zare $^{2,}$ \\ ${ }^{1}$ Department of Biotechnology, Science and Research Branch, Islamic Azad University, Tehran, IR Iran \\ ${ }^{2}$ Skin and Stem Cell Research Center, Tehran University of Medical Sciences, Tehran, IR Iran \\ ${ }^{3}$ Applied Biophotonics Research Center, Science and Research Branch, Islamic Azad University, Tehran, IR Iran \\ "Corresponding author: Mehrak Zare, Skin and Stem Cell Research Center, Tehran University of Medical Sciences, Tehran, IR Iran. E-mail: mehrakzare@gmail.com
}

Received 2017 February 14; Accepted 2017 February 27.

\begin{abstract}
Context: Scars result from prolonged inflammatory phases and abnormal fibroproliferative responses in wounds. Regardless of beauty considerations that have profound psychological and social effects, scars can also have physical effects, such as growth constraints in children. Applying molecular and cellular mechanisms imitating the fetal scarless wound healing, brings about new and effective therapeutic strategies for alleviating scars. This review concentrated on innovative approaches, which simultaneously target multiple effective pathways in reducing scars.

Evidence Acquisition: The most outstanding products for reducing scars, were TGF- $\beta 3$ and IL-10, which failed in phase III clinical trial on their way to reach the market. In this review, multi-targeting remedies for reducing scars and their effective in vitro and in vivo mechanisms are discussed in details. There is also evidence in translation of these investigations to clinical trials.

Results: MiRNAs are unique molecular components with pleiotropic actions, which target multiple signaling pathways in scars at the same time. Fetal cells, mesenchymal stem cells, and oral mucosal cells secrete a natural relevant concentration of growth factors and cytokines that are effective in scar reduction. Fat grafting is a promising treatment for scars, providing an appropriate extra cellular matrix with homing mesenchymal stem cells.

Conclusions: Increasing the concentration of one growth factor or cytokine overexpressed in fetal scarless wound healing is not sufficient individually in scar reduction. Despite the profound effects of cells in scars, using biomimetic materials, which mimic the fetal cell microenviroment, should also be taken into account.
\end{abstract}

Keywords: scarless Wound Healing, miRNA, Fetal Cells, Mesenchymal Stem Cell, Oral Mucosa, Fat Grafting

\section{Context}

Scars are distressing memorial signs of a healed wound, which can remain all through the life of a patient. Approaches to optimize the healing process of wounds will minimize the development of hypertrophic scars. Improving strategies in scar treatments are an imitation of what happens in fetal scarless wound healing. The longevity and severity of wound healing phases are different in regular, fibrotic, and scarless wound healing. The inflammation phase is very short and the proliferation and remodeling phases overlap in fetal wound healing. Applying molecular and cellular mechanisms underlying this profile brings about new and effective therapeutic strategies for elevating scars. There are several useful studies targeting signaling pathways, such as TGF $\beta$ and Wnt signaling, in scar formation, which none the less could be sufficient individually in scar reduction. Thus, therapeutic plans should be based on targeting relevant concentrations of proteins and their activities. Novel miRNA approaches, as posttranscriptional regulators of multiple proteins and associated pathways, have become an emerging field of interest. The use of fetal cells as the main source of scarless wound healing is beneficial in skin substitute constructions. Cell banks from fetal skin are being developed in short periods of time and with minimal cell culturing requirements and can be easily scaled out. Mesenchymal stem cells are valuable cell sources with their specific characteristics, such as high immuno-modulatory effects in scar environment and unique secreting growth factors, which stimulate keratinocyte migration and increase anti-fibrotic matrix metalloproteinase. Wound healing is commonly quicker and associated with less scarring in the oral mucosa than in the skin, therefore oral mucosal equivalents may contribute to fast and scarless wound healing.

Also, fat grafting is a promising treatment in scars due to mesenchymal stem cells homing in its SVF proportion. 


\section{Evidence Acquisition}

More than 100 million patients in industrialized countries are effected by scars each year, which imposes a heavy financial burden on medical care systems (1). Skin health effects the physiological homeostasis of the human body. Skin is the largest organ of the body, which plays an essential role in protecting the body against mechanical forces, infections, fluid imbalances, and temperature disturbances (2). Wound healing is a defense mechanism against infection and further damage, which is mediated by fibroproliferative response resulted in scar formation (3). The major goals of the treatment of wounds are rapid wound closure in order to restore the protective barrier immediately $(4,5)$. Scars resulted from pathologic wounds are caused by abnormal fibroproliferative responses and regardless of beauty considerations and deformation that has profound psychological and social effects, they cause devastating disabilities in children with severe burn injuries. They can also have physical effects, such as growth constraints in children and reduce their quality of life (68).

Considering the importance of scarless wound healing, therapeutic strategies are expanding, which are categorized to 2 general groups: molecular based therapies and cell based therapies.

The most outstanding molecules involved in molecular based therapies of wounds without scars, were TGF$\beta 3$ and IL-10, which failed in phase III clinical trials (9). Among different types of molecular-based therapies, miRNAs are the most promising molecules because one miRNA could target more than 100 genes. Accordingly, miRNA molecules are different from other molecules because of pleiotropic actions through different signaling pathways (10).

Since most molecular-based therapies are not adequate individually and have limitations for scarless wound healing, cell-based therapies have attracted much attentions. There are many different kinds of cell sources for cell-based therapies of wounds in a scarless manner, such as fetal skin cells, mesenchymal stem cells, and oral mucosal cells. Fat grafting may also be considered as a cellbased therapy because its effectiveness is dependent on mesenchymal stem cells in its SVF proportion $(1,11)$.

Here, this study focused on the most important scarless wound healing strategies, which have been practiced all over the world.

\section{1. miRNAs and Scarless Wound Healing}

Recent advances have indicated that MicroRNAs play pivotal roles in scarless wound healing (10). miRNAs are defined as a highly conserved family of small noncoding, endogenous single stranded RNA molecules, with an average length of 22 nucleotides that post-transcriptionally repress their target mRNAs in a sequence-specific inhibition manner, predominately by pairing the 6 to 8 nucleotide site in seed sequence of miRNA to 3'UTR of mRNA (12-14).

miRNAs are primarily transcribed by RNA polymerase II to a long initial transcript or pri-miRNA. The pri-miRNA is processed to a shorter hairpin-shaped, double-stranded precursor miRNAs (pre-miRNAs) of approximately $70 \mathrm{nu}$ cleotides in length, by Drosha and Pasha/DGCR8. The resulting premiRNAs, with 2 nucleotides overhanging at their 3' ends, have binding sites for RAN GTPase/exportin5 that cause translocation of premiRNAs to the cytoplasm. Another RNA-specific nuclease, Dicer, cleaves the pre-miRNAs to 18- to 24-nt double-stranded RNAs. The resulting RNA duplex incorporates with the miRISC, where one of the strands is degraded while the guide strand becomes the mature miRNA. These mature miRNA guides miRISC to the target sequences by binding to complementary regions within the 3'UTR of the target mRNA and their degree of complementarity determines the inhibition of mRNA translation (imperfect matching) or cleavage of mRNA (perfect or near perfect matching) (15-18).

miRNA-based therapy in the field of dermatology is in its early stage, yet the initial findings are considerable, indicating that there are vast opportunities for developing effective therapies for scarless wound healing. Considering the important roles of miRNAs in skin development and pathology, it was assumed that miRNAs participate broadly in transition of scarless phenotype to a scarred phenotype during development. The comparison of genome-wide profiling of miRNAs showed that miR-29b and miR-29c are differently expressed between mid-gestational (E-16 day) and late-gestational periods (E19 day). Their potential targets include Smads, $\beta$ catenin, and Ras, which were involved in several signaling pathways and ECM remodeling critical to scarless wound healing (19). MiR-192 has been demonstrated to be regulated by $\operatorname{TGF} \beta$ and might perform its role by maintaining the scarless phenotype (19-21). The altered expression of miR-34 family (which target TGF $\beta$ ) in mid-gestation fetal keratinocyte, in comparison with late-gestation fetal keratinocyte, may contribute to less scar formation. The MiR-34 family suppresses the expression of genes involved in the TGF- $\beta$ pathway, such as TGF- $\beta 3$, TGF- $\beta$ RI, TGF- $\beta$ RII, SMAD3, SMAD4, and SAR1A $(22,23)$.

Additionally, studies have shown that inhibition of miR-145 shows a significant decrease in type I collagen expression, TGF- $\beta 1$ secretion, and contractility in skin myofibroblasts, which could have roles in scar reduction (24, 25). Furthermore, overexpression of miR-149 could downregulate the expression of pro-inflammatory cytokines, such as IL-1 $\alpha$, IL-1 $\beta$, and IL- 6 in inflammatory conditions and also indirectly accelerate the expression of TGF-BIII 
and collagen type III in fibroblasts (26).

Another miR, which targets TGF $\beta-1$ is miR-185, which also targets collagen-1 in hypertrophic scar fibroblasts (27). Taken together, all these miRNAs could be promising targets for scarless wound healing.

\subsection{Fetal Cell Therapy and Scarless Wound Healing}

Since fetal wounds heal without a scar early in gestation, it may hold the key to scarless repair. In fact, the fetus has a more efficient regeneration system to quickly restore tissue integrity and heal the wound in a scarless manner while adults' wounds are repaired with the formation of scar (28). Among different kinds of cells used for cell-based therapies for wound management of the skin, fetal cells present biological, technical, and therapeutic advantages over others, for instance they are differentiated cells with low immunogenic and high expansion and regeneration characteristics (29).

Their cytokine and growth factor expression profiles are also different from adult cells. Central to this different cytokine expression profile, is the TGF- $\beta$ family, which has been most widely studied as it is implicated in the transition between scarless healing and repair with scar formation. There are 3 highly homologous isoforms of TGF- $\beta$ known in humans, including TGF- $\beta 1$, TGF- $\beta 2$, and TGF- $\beta 3$. The relative proportion of TGF- $\beta$ isoform determines the wound repair outcome $(30,31)$.

Besides, they are able to secrete more VEFG-A, and fetal fibroblasts and keratinocytes demonstrate no expression of MHC class II with the low expression of MHC class I (HLAA, $-\mathrm{B}$ and $-\mathrm{C}$ ). They also show expression of indoleamine 2,3 dioxygenase (IDO-1 and - 2), which has immunomodulatory effect on T-cells (32). Their collagens are mainly (30\% to $60 \%$ ) collagen type III, which is composed of smaller and finer fibers than type I that produces higher reticular pattern of fiber deposition in the fetus. They can also proliferate and produce collagen at the same time, and stimulate extra cellular matrix replacement directly or indirectly in tissue repair process for migration to the wound area. Their capability to adapt to biomaterials and strong resistance to oxidative and physical stresses in wound environment, may lead to their durability in the wound milieu (29, 33). Scarless wound healing in fetal skin at early gestation is a result of the unique cytokine or growth factor profile. Considering all these advantages, fetal cells are considered to be a potent candidate for scarless wound healing-based therapies.

Since fetal cells have the advantage of being an organ donation, only very small biopsies are required for developing extensive and stable master cell banks for many tissues. In 2005, Hohlfeld et al. used tissue engineered fetal skin seeded on collagen sheets for 8 children with burns and mean time to healing for the burns was 15.3 days after the first construct application. The results were satisfactory in all 8 children, showing little hypertrophy of new skin (34). In another study, the capacity of fetal cells associated with collagen matrix for treating various wounds was analyzed. Their results indicated that fetal cells accelerated the repair process and reduced scarring in severe burns and wounds of various nature in children (35). Ramelet et al. evaluated the tolerance of several treatments with fetal cell biological bandages and interaction with the chronic wound environment. Their data demonstrated that the fetal skin construct had promising results for both chronic wounds and severe burns (36). In 2013, Zuliani et al. applied fetal fibroblasts and keratinocytes to stimulate wound repair by allogeneic fetal cell-based dressing for acute and chronic wounds. They showed that direct interaction between fetal fibroblast and keratinocytes strongly enhanced wound healing growth factor and had therapeutic benefits over fetal fibroblast cells, individually (32). In 2015, Larijani and Ghahari suggested that applying human fetal skin fibroblast alone or in combination with biocompatible scaffold could be beneficial for treatment of ulcers, such as diabetic wounds (29).

\subsection{Mesenchymal Stem Cells and Scarless Wound Healing}

Adult mesenchymal cells that contribute to the normal healing process of the wound are tissue repair mediators. These cells reduce the inflammation of the wound and reprogram the resident cells and immune cells in order to regenerate the tissue and achieve anti-fibrotic effects. Since in the mammalian fetus healing of the wound is performed without any scar, researchers have made great efforts to model embryonic tissue to devise effective methods for treating wounds. The most prominent of these methods were using Avotermin (TGF $\beta 3$ ) and IL-10 (ilodecakin), which failed in phase III clinical trials. It was indicated that molecular-based methods individually, did not have the potential to treat wounds in a scarless fashion (37, 38).

Recent studies clearly revealed that cell-based therapies are much more powerful than molecular based methods in scarless wound healing.

Adult mesenchymal stem cells express the most signaling molecules involved in the simulation of an environment without a scar, such as TGF $\beta 3$, IL-10, and 2,3- dioxygenase indolamin and so on, which have immunomodulatory characteristics involved in wound healing with less scar. Thus, mesenchymal stem cells could be considered as an appropriate candidate for cell therapy to heal a wound without scars $(39,40)$.

Another characteristic of mesenchymal stem cells, which could be applied in scarless wound healing, is their 
conditioned media. Exploring the paracrine effects of mesenchymal stem cells on dermal fibroblasts indicated that the proliferation, migration, and the ratio of matrix metalloproteinase to tissue inhibitor of metalloproteinases of fibroblasts increased yet the ratio of TGF- $\beta 1 / 3$ was reduced and they transitioned to a phenotype with a lower myofibroblast formation capacity $(41,42)$.

Seo et al. found that local injection of heterogeneous mixture of 2 million amniotic fluid-derived mesenchymal stem cells and amniotic membrane into the postsurgical scar reduced pain and scarring (43). The use of lipid grafts, which is a source of mesenchymal stem cells, has also led to a reduction in both neuropathic and hypertrophic scars. lipo grafts enriched by mesenchymal stem cells have been used in two studies evaluating their effectiveness on healing chronic ulcers caused by radiation in 10 individuals (44). In another study, 29 cases underwent the injection of lipograft enriched with MSC for removing soft tissue defects. The results of these investigations indicated that lipograft enriched by MSC improves wound healing, increases the effect of fat transplantation, and prevents deep tissue fibrosis and skin scarring (45).

Several studies have been carried out on the efficacy of mesenchymal stem cells in wound healing in multiple animal models. However, due to the fact that laboratory animals like rats and mouse have loose skin, wound healing does not lead to scarring. The model of burn in pigs is the closest model to the creation of scars in humans. Most animal studies have focused on the effectiveness of MSCs in wound healing, and have paid less attention to prevent scarring after wound closure. In 2012, Yun et al. evaluated the effect of adipose-derived stem cells on scar formation and remodeling. They created full-thickness defects on the dorsal skin of pigs and after 50 days, when the defects transformed to scars, they injected 106 adipose-derived stem cells into the scar of the full thickness wound on the back of the porcine models. The results indicated that the scars were reduced, collagen pattern was improved, the number of mast cells was decreased, the expression of TIMP1 and $\alpha$ SMA genes was decreased, and the expression of MMP1 gene was increased (46).

In 2015, Zhang et al. investigated the efficiency of intralesional injection of adipose derived mesenchymal stem cell on a hypertrophic scarring in a rabbit ear model. A fullthickness wound was made on the back of the ear of rabbits and $4 \times 10^{6}$ cells were locally injected 14 days later. The conditioned media was also employed as a control. The histological results, ultrasonography, and the level of $\alpha \mathrm{SMA}$ gene expression demonstrated the reduction in scar size in relation to internal control 35 days after injection (47). In a recently published research, the secretory exosomes from adipose-derived mesenchymal stem cells caused scarless wound healing by regulating extracellular matrix re- modeling. It was found that intravenous injection of exosomes secreted by adipose mesenchymal stem cells caused the level of TGF $\beta 3$ to increase in relation to TGF $\beta 1$ and prevented fibroblasts from differentiating to myofibroblasts (48).

\subsection{Oral Mucosa and Scarless Wound Healing}

The first and most obvious difference between skin and mucosa is their different environment; mucosa has a humid environment as a result of salivary and microflora yet findings indicated that wound healing in oral mucosa is likely to involve intrinsic features of mucosal tissue and is not only owing to environmental factors (49).

Although healing of both dermal wounds and oral mucosa progresses through the same stages, involving hemostasis, inflammation, proliferation, and remodeling of the collagen matrix yet there are differences in fibroblast, macrophage, and neutrophil activity at various stages of wound healing. Moreover, in oral mucosa, response to the injury are commonly more rapid and with less inflammation and angiogenesis than in the skin, with minimal or no scar formation. Mucosal wounds show a lower inflammatory response with lower neutrophil, macrophage, and T-cell infiltration, as well as decreased expression of proinflammatory TGF- $\beta 1$, yet the level of TGF- $\beta 3$ expression, which has anti-fibrotic properties in oral mucosa has increased.

Moreover, in oral wounds, remodeling of the wound matrix seems to be quicker than skin wounds (50). It was demonstrated that oral mucosa equivalents (sheet) containing oral keratinocytes and oral fibroblasts may have a role in rapid scarless wound healing. The skin and oral mucosa vary in their histology of each tissue, and keratinocytes from these 2 sites differ in function (51). A previous investigation suggested that differences in response to injury between oral and skin keratinocytes are revealed in gene expression profiles. It was found that 13,710 genes are differently expressed between oral mucosa and the skin. These differently expressed genes might affect keratinocytes and cause skin keratinocytes to show lower intrinsic proliferation and migration capacities than those of oral keratinocytes (52). Also, the cellular response to injury in mucosa and skin are different. There are also differences between fibroblasts in oral mucosa and skin. Dermal fibroblasts proliferated less than mucosal fibroblasts and showed a greater collagen gel contraction because of a greater response to TGF $\beta 1$ (53) (Figure 1).

\subsection{Fat Grafting and Scarless Wound Healing}

Fat is abundant and easily accessible, and for the first time in 1912, it was used for the treatment of facial lipoatrophy by Eugene Holler (54). In 1992, Coleman described 


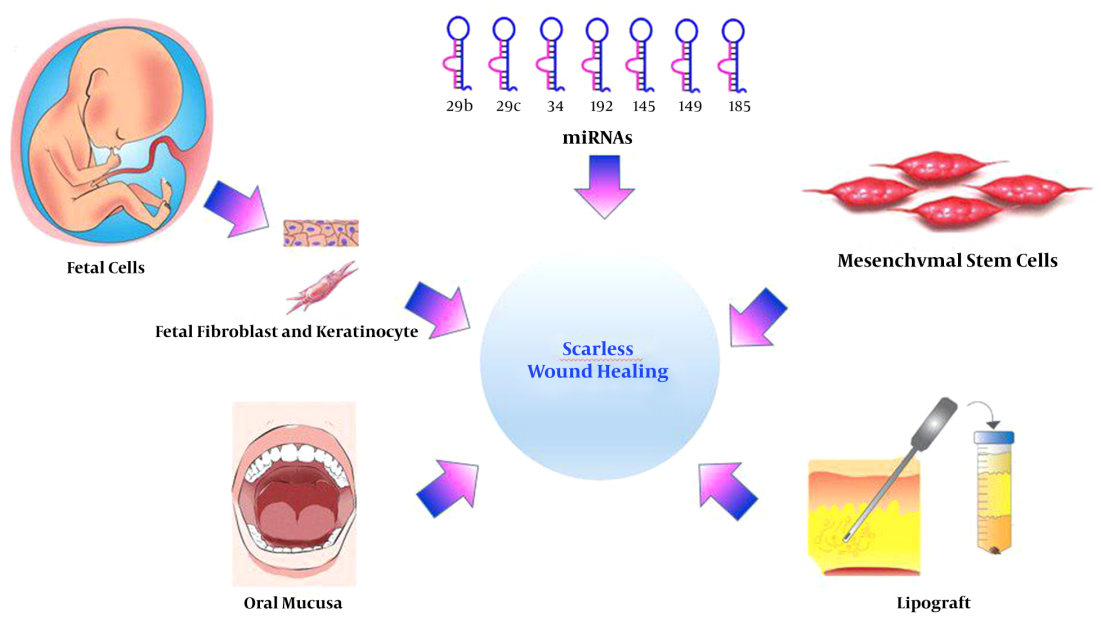

Figure 1. A schematic Representation of Effective Strategies in Reducing Scars

a new technique for increasing survival of adipose cells, and nowadays his method is widely used (55). Adipose tissue contains cellular and extracellular matrix components with stem cells in its cellular component, which are capable of differentiating to other cells, such as cartilage, bone, nerve or muscle (56). These cells show less potential than embryonic cells yet compared with bone marrow stem cells, they are easily harvested (55). Lipotransfer seems to improve the structural features of the extracellular matrix and increase its production (57). Histologic assessment after fat transfer revealed new collagen synthesis and dermal hyperplasia with hypervascularity, which was observed locally (55) and in a molecular study, results demonstrated downregulation of fibrotic markers along with upregulation of vasculogenic markers documented using both techniques (58). Jaspers et al. demonstrated the influence of fat grafting on functional scar parameters, such as pliability and overall scar quality in a 3-month follow up and sustainable effectiveness of single-treatment fat transfer after a 12-month assessment $(59,60)$. Sardesai suggested that lipotransfer appears to improve dermal characteristics, including elasticity, skin thickness, stiffness, and pliability with quantitative and qualitative analysis (61). The exact mechanism of these changes is yet unknown but one hypothesis for the dermal improvement other than direct influence of fat on surrounding tissue, is adhesiolysis. In addition, after fat grafting, perivascular adipose stem cells may result in adipocyte regeneration and revascularization (59). Rapp et al. studied the effect of autologous fat and adipose-derived progenitor stromal cells on swine hypertrophic burn scars and revealed a decrease in scar thickness and reduction in inflammatory profile with altered fibroblast gene expression in RNA se- quencing (62).

\section{Results}

In this review, the known modalities of scarless wound healing, with a focus on cell based therapies, are discussed. Due to the pleiotropic effect that miRNA could exert on scarless wound healing, miRNA-based therapy is considered as the only molecular based strategy that attempts to achieve scarless wound healing in adults, whether through fetal mimicry or attenuating fibrotic response. Fetal cells, mesenchymal stem cells, oral mucosa, and fat grafting are investigated completely. Because the effectiveness of fat grating is associated with its mesenchymal stem cell, this study included it in cell-based therapy. This study attempted to clarify promising clinical targets and evaluated therapeutic strategies currently in practice.

\section{Conclusions}

Considering all the major experimental and clinical strategies in order to achieve scarless wound healing, it is apparent that most can decrease scar thickness and appearance yet will not generate histological or functional similarity to uninjured skin. Since fetal wound healing is a remarkable process that is primarily different from postnatal healing, it occurs rapidly and without any scar, and offers promising insight for wound healing in a scarless fashion. However, because the factors responsible for the fetal wound healing phenotype were originally ascribed to the intrauterine environment, this has been demonstrated to be neither necessary nor sufficient for scarless healing. The capability of regeneration is now believed to 
be intrinsic to the tissue itself, and is closely associated with fetal dermal constitution. Consequently, once cellbased therapies will be effective that they were placed in a niche where their normal physiologic condition could be induced with high accuracy. Therefore, using biomimetic materials, which mimic extracellular matrix and produce structural support, is essential.

Current trends in scarless wound healing strategies combine cell-based therapies and regenerative medicine in order to accomplish better results.

\section{Footnote}

Conflict of Interest: The authors declare no conflicts of interest.

\section{References}

1. Walmsley GG, Maan ZN, Wong VW, Duscher D, Hu MS, Zielins ER, et al. Scarless wound healing: chasing the holy grail. Plast Reconstr Surg. 2015;135(3):907-17. doi: 10.1097/PRS.0000000000000972. [PubMed: 25719706].

2. Sorg H, Tilkorn DJ, Hager S, Hauser J, Mirastschijski U. Skin wound healing: an update on the current knowledge and concepts. Eur Surg Res. 2017;58(1-2):81-94.

3. Hu MS, Maan ZN, Wu JC, Rennert RC, Hong WX, Lai TS, et al. Tissue engineering and regenerative repair in wound healing. Ann Biomed Eng. 2014;42(7):1494-507. doi: 10.1007/s10439-014-1010-z. [PubMed: 24788648].

4. Gurtner GC, Werner S, Barrandon Y, Longaker MT. Wound repair and regeneration. Nature. 2008;453(7193):314-21. doi: 10.1038/nature07039. [PubMed: 18480812].

5. Singer AJ, Clark RA. Cutaneous wound healing. $N$ Engl J Med. 1999;341(10):738-46. doi: 10.1056/NEJM199909023411006. [PubMed: 10471461].

6. Cass DL, Meuli M, Adzick NS. Scar wars: implications of fetal wound healing for the pediatric burn patient. Pediatr Surg Int.1997;12(7):4849. doi: 10.1007/BF01258707. [PubMed: 9238112].

7. Asuku ME, Ibrahim A, Ijekeye FO. Post-burn axillary contractures in pediatric patients: a retrospective survey of management and outcome. Burns. 2008;34(8):1190-5.

8. Egeland B, More S, Buchman SR, Cederna PS. Management of difficult pediatric facial burns: reconstruction of burn-related lower eyelid ectropion and perioral contractures. J Craniofac Surg. 2008;19(4):960-9. doi: 10.1097/SCS.0b013e318175f451. [PubMed: 18650718].

9. Leung A, Crombleholme TM, Keswani SG. Fetal wound healing: implications for minimal scar formation. Curr Opin Pediatr. 2012;24(3):371-8. doi: 10.1097/MOP.ob013e3283535790. [PubMed: 22572760].

10. Pastar I, Ramirez H, Stojadinovic O, Brem H, Kirsner RS, Tomic-Canic M. Micro-RNAs: New Regulators of Wound Healing. Surg Technol Int. 2011;21:51-60. [PubMed: 22504970].

11. Leavitt T, Hu MS, Marshall CD, Barnes LA, Lorenz HP, Longaker MT. Scarless wound healing: finding the right cells and signals. Cell Tissue Res. 2016;365(3):483-93. doi: 10.1007/s00441-016-2424-8. [PubMed: 27256396].

12. Huang Y, Shen XJ, Zou Q, Wang SP, Tang SM, Zhang GZ. Biological functions of microRNAs: a review. J Physiol Biochem. 2011;67(1):129-39. doi: 10.1007/s13105-010-0050-6. [PubMed: 20981514].

13. Cai Y, Yu X, Hu S, Yu J. A brief review on the mechanisms of miRNA regulation. Genomics Proteomics Bioinformatics. 2009;7(4):147-54. doi: 10.1016/S1672-0229(08)60044-3. [PubMed: 20172487].
14. Bartel DP. MicroRNAs: genomics, biogenesis, mechanism, and function. Cell. 2004;116(2):281-97. [PubMed: 14744438].

15. Meister G, Tuschl T. Mechanisms of gene silencing by double-stranded RNA. Nature. 2004;431(7006):343-9. doi: 10.1038/nature02873. [PubMed: 15372041].

16. Filipowicz W, Jaskiewicz L, Kolb FA, Pillai RS. Post-transcriptional gene silencing by siRNAs and miRNAs. Curr Opin Struct Biol. 2005;15(3):33141. doi: 10.1016/j.sbi.2005.05.006. [PubMed:15925505].

17. Krol J, Loedige I, Filipowicz W. The widespread regulation of microRNA biogenesis, function and decay. Nat Rev Genet. 2010;11(9):597610. doi: 10.1038/nrg2843. [PubMed: 20661255].

18. Treiber T, Treiber N, Meister G. Regulation of microRNA biogenesis and function. Thromb Haemost. 2012;107(4):605-10. doi: 10.1160/TH1112-0836. [PubMed: 22318703].

19. Cheng J, Yu H, Deng S, Shen G. MicroRNA profiling in mid- and lategestational fetal skin: implication for scarless wound healing. Tohoku JExp Med. 2010;221(3):203-9. [PubMed: 20543536].

20. Kato M, Zhang J, Wang M, Lanting L, Yuan H, Rossi JJ, et al. MicroRNA192 in diabetic kidney glomeruli and its function in TGF-beta-induced collagen expression via inhibition of E-box repressors. Proc Natl Acad Sci U S A. 2007;104(9):3432-7. doi: 10.1073/pnas.0611192104. [PubMed: 17360662].

21. Krupa A, Jenkins R, Luo DD, Lewis A, Phillips A, Fraser D. Loss of MicroRNA-192 promotes fibrogenesis in diabetic nephropathy. J Am Soc Nephrol. 2010;21(3):438-47. doi: 10.1681/ASN.2009050530. [PubMed: 20056746].

22. Zhao F, Wang Z, Lang H, Liu X, Zhang D, Wang X, et al. Dynamic EXpression of Novel MiRNA Candidates and MiRNA-34 Family Members in Early- to Mid-Gestational Fetal Keratinocytes Contributes to Scarless Wound Healing by Targeting the TGF-beta Pathway. PLoS One. 2015;10(5). e0126087. doi: 10.1371/journal.pone.0126087. [PubMed: 25978377].

23. Horsburgh S, Fullard N, Roger M, Degnan A, Todryk S, Przyborski $S$, et al. MicroRNAs in the skin: role in development, homoeostasis and regeneration. Clin Sci (Lond). 2017;131(15):1923-40. doi: 10.1042/CS20170039. [PubMed: 28705953].

24. Mills SJ, Cowin AJ. MicroRNAs and their roles in wound repair and regeneration. Wound Pract Res J Aust Wound Manag Assoc. 2013;21(1):26.

25. Gras C, Ratuszny D, Hadamitzky C, Zhang H, Blasczyk R, Figueiredo C. miR-145 Contributes to Hypertrophic Scarring of the Skin by Inducing Myofibroblast Activity. Mol Med. 2015;21:296-304. doi: 10.2119/molmed.2014.00172. [PubMed: 25876136].

26. Lang H, Zhao F, Zhang T, Liu X, Wang Z, Wang R, et al. MicroRNA149 contributes to scarless wound healing by attenuating inflammatory response. Mol Med Rep. 2017;16(2):2156-62. doi: 10.3892/mmr.2017.6796. [PubMed: 28627609].

27. Xiao K, Luo X, Wang X, Gao Z. MicroRNA185 regulates transforming growth factorbeta1 and collagen1 in hypertrophic scar fibroblasts. Mol Med Rep. 2017;15(4):1489-96. doi: 10.3892/mmr.2017.6179. [PubMed: 28259900].

28. Larson BJ, Longaker MT, Lorenz HP. Scarless fetal wound healing: a basic science review. Plast Reconstr Surg. 2010;126(4):1172-80. doi: 10.1097/PRS.0b013e3181eae781. [PubMed: 20885241].

29. Larijani B, Ghahari A, Warnock GL, Aghayan HR, Goodarzi P, Falahzadeh K, et al. Human fetal skin fibroblasts: Extremely potent and allogenic candidates for treatment of diabetic wounds. Med Hypotheses. 2015;84(6):577-9. doi: 10.1016/j.mehy.2015.03.004. [PubMed: 25784640].

30. Hirt-Burri N, Ramelet AA, Raffoul W, de Buys Roessingh A, Scaletta C, Pioletti D, et al. Biologicals and fetal cell therapy for wound and scar management. ISRN Dermatol. 2011;2011:549870. doi: 10.5402/2011/549870. [PubMed: 22363853].

31. Hirt-Burri N, Scaletta C, Gerber S, Pioletti DP, Applegate LA. Woundhealing gene family expression differences between fetal and foreskin cells used for bioengineered skin substitutes. Artif Organs. 2008;32(7):509-18. doi: 10.1111/j.1525-1594.2008.00578.x. [PubMed: 18638304]. 
32. Zuliani T, Saiagh S, Knol AC, Esbelin J, Dreno B. Fetal fibroblasts and keratinocytes with immunosuppressive properties for allogeneic cell-based wound therapy. PLoS One. 2013;8(7). e70408. doi 10.1371/journal.pone.0070408. [PubMed: 23894651].

33. Applegate LA, Scaletta C, Hirt-Burri N, Raffoul W, Pioletti D. Whole-cell bioprocessing of human fetal cells for tissue engineering of skin. Skin Pharmacol Physiol. 2009;22(2):63-73. doi:10.1159/000178865. [PubMed: 19188754].

34. Hohlfeld J, de Buys Roessingh A, Hirt-Burri N, Chaubert P, Gerber S, Scaletta C, et al. Tissue engineered fetal skin constructs for paediatric burns. Lancet. 2005;366(9488):840-2. doi: 10.1016/S01406736(05)67107-3. [PubMed:16139659].

35. De Buys Roessingh AS, Hohlfeld J, Scaletta C, Hirt-Burri N, Gerber S, Hohlfeld P, et al. Development, Characterization, and Use of a Fetal Skin Cell Bank for Tissue Engineering in Wound Healing. Cell Transplant. 2017;15(8-9):823-34. doi:10.3727/000000006783981459.

36. Ramelet AA, Hirt-Burri N, Raffoul W, Scaletta C, Pioletti DP, Offord E, et al. Chronic wound healing by fetal cell therapy may be explained by differential gene profiling observed in fetal versus old skin cells. Exp Gerontol.2009;44(3):208-18. doi: 10.1016/j.exger.2008.11.004. [PubMed: 19049860].

37. Jackson WM, Nesti LJ, Tuan RS. Mesenchymal stem cell therapy for attenuation of scar formation during wound healing. Stem Cell Res Ther 2012;3(3):20. doi:10.1186/scrt111. [PubMed: 22668751].

38. Jackson WM, Nesti LJ, Tuan RS. Concise review: clinical translation of wound healing therapies based on mesenchymal stem cells Stem Cells Transl Med. 2012;1(1):44-50. doi: 10.5966/sctm.2011-0024. [PubMed: 23197639].

39. Ennis WJ, Sui A, Bartholomew A. Stem Cells and Healing: Impact on Inflammation. Adv Wound Care (New Rochelle). 2013;2(7):369-78. doi: 10.1089/wound.2013.0449. [PubMed: 24587974].

40. Gao F, Chiu SM, Motan DA, Zhang Z, Chen L, Ji HL, et al. Mesenchymal stem cells and immunomodulation: current status and future prospects. Cell Death Dis. 2016;7. e2062. doi: 10.1038/cddis.2015.327. [PubMed: 26794657].

41. Hocking AM, Gibran NS. Mesenchymal stem cells: paracrine sig naling and differentiation during cutaneous wound repair. Exp Cell Res. 2010;316(14):2213-9. doi: 10.1016/j.yexcr.2010.05.009. [PubMed: 20471978].

42. Chen L, Tredget EE, Wu PY, Wu Y. Paracrine factors of mesenchymal stem cells recruit macrophages and endothelial lineage cells and enhance wound healing. PLoS One. 2008;3(4). e1886. doi: 10.1371/journal.pone.0001886. [PubMed: 18382669].

43. Seo BF, Jung SN. The Immunomodulatory Effects of Mesenchymal Stem Cells in Prevention or Treatment of Excessive Scars. Stem Cells Int 2016;2016:6937976. doi: 10.1155/2016/6937976. [PubMed: 26839566].

44. Akita S, Yoshimoto H, Ohtsuru A, Hirano A, Yamashita S. Autologous adipose-derived regenerative cells are effective for chronic in tractable radiation injuries. Radiat Prot Dosimetry. 2012;151(4):656-60. doi: 10.1093/rpd/ncs176. [PubMed: 22914335].

45. Spiekman M, van Dongen JA, Willemsen JC, Hoppe DL, van der Lei B, Harmsen MC. The power of fat and its adipose-derived stromal cells: emerging concepts for fibrotic scar treatment.J Tissue Eng Regen Med. 2017;11(11):3220-35. doi: 10.1002/term.2213. [PubMed: 28156060].

46. Yun IS, Jeon YR, Lee WJ, Lee JW, Rah DK, Tark KC, et al. Effect of human adipose derived stem cells on scar formation and remodeling in a pig model: a pilot study. Dermatol Surg. 2012;38(10):1678-88. doi: 10.1111/j.1524-4725.2012.02495.x. [PubMed: 22804839].

47. Zhang Q, Liu LN, Yong Q, Deng JC, Cao WG. Intralesional injection of adipose-derived stem cells reduces hypertrophic scarring in a rabbit ear model. Stem Cell Res Ther. 2015;6:145. doi: 10.1186/s13287-015-0133-y. [PubMed: 26282394]
48. Wang L, Hu L, Zhou X, Xiong Z, Zhang C, Shehada HMA, et al. Exosomes secreted by human adipose mesenchymal stem cells promote scarless cutaneous repair by regulating extracellular matrix remodelling. Sci Rep. 2017;7(1):13321. doi: 10.1038/s41598-017-12919-x. [PubMed: 29042658].

49. Mak K, Manji A, Gallant-Behm C, Wiebe C, Hart DA, Larjava H, et al. Scarless healing of oral mucosa is characterized by faster resolution of inflammation and control of myofibroblast action compared to skin wounds in the red Duroc pig model. $J$ Dermatol Sci. 2009;56(3):168-80. doi: 10.1016/j.jdermsci.2009.09.005. [PubMed: 19854029].

50. Szpaderska AM, Zuckerman JD, DiPietro LA. Differential injury responses in oral mucosal and cutaneous wounds. J Dent Res. 2003;82(8):621-6. doi: 10.1177/154405910308200810. [PubMed: 12885847].

51. Roh JL, Lee J, Kim EH, Shin D. Plasticity of oral mucosal cell sheets for accelerated and scarless skin wound healing. Oral Oncol. 2017;75:81-8. doi: 10.1016/j.oraloncology.2017.10.024. [PubMed: 29224829].

52. Turabelidze A, Guo S, Chung AY, Chen L, Dai Y, Marucha PT, et al. Intrinsic differences between oral and skin keratinocytes. PLoS One. 2014;9(9). e101480. doi: 10.1371/journal.pone.0101480. [PubMed: 25198578].

53. Shannon DB, McKeown ST, Lundy FT, Irwin CR. Phenotypic differences between oral and skin fibroblasts in wound contraction and growth factor expression. Wound Repair Regen. 2006;14(2):172-8. doi: 10.1111/j.1743-6109.2006.00107.x. [PubMed: 16630106].

54. Coleman SR. Structural fat grafting: more than a permanent filler. Plast Reconstr Surg. 2006;118(3 Suppl):108S-20S. doi: 10.1097/01.prs.0000234610.81672.e7. [PubMed: 16936550].

55. Simonacci F, Bertozzi N, Grieco MP, Grignaffini E, Raposio E. Procedure, applications, and outcomes of autologous fat grafting. Ann Med Surg (Lond). 2017;20:49-60. doi: 10.1016/j.amsu.2017.06.059. [PubMed: 28702187].

56. Tsuji W, Rubin JP, Marra KG. Adipose-derived stem cells: Implications in tissue regeneration. World J Stem Cells. 2014;6(3):312-21. doi: 10.4252/wjsc.v6.i3.312. [PubMed: 25126381].

57. Banyard DA, Borad V, Amezcua E, Wirth GA, Evans GR, Widgerow AD. Preparation, Characterization, and Clinical Implications of $\mathrm{Hu}$ man Decellularized Adipose Tissue Extracellular Matrix (hDAM): A Comprehensive Review. Aesthet Surg J. 2016;36(3):349-57. doi: 10.1093/asj/sjvi70. [PubMed: 26333991].

58. Sultan SM, Barr JS, Butala P, Davidson EH, Weinstein AL, Knobel D, et al. Fat grafting accelerates revascularisation and decreases fibrosis following thermal injury. J Plast Reconstr Aesthet Surg. 2012;65(2):219-27. doi: 10.1016/j.bjps.2011.08.046. [PubMed: 21962530].

59. Jaspers ME, Brouwer KM, van Trier AJ, Groot ML, Middelkoop E, van Zuijlen PP. Effectiveness of Autologous Fat Grafting in Adherent Scars: Results Obtained by a Comprehensive Scar Evaluation Protocol. Plast Reconstr Surg. 2017;139(1):212-9. doi:10.1097/PRS.0000000000002891. [PubMed: 27632398].

60. Jaspers MEH, Brouwer KM, van Trier AJM, Middelkoop E, van Zuijlen PPM. Sustainable effectiveness of single-treatment autologous fat grafting in adherent scars. Wound Repair Regen. 2017;25(2):316-9. doi: 10.1111/wrr.12521. [PubMed: 28370844].

61. Sardesai MG, Moore CC. Quantitative and qualitative dermal change with microfat grafting of facial scars. Otolaryngol Head Neck Surg. 2007;137(6):868-72. doi: 10.1016/j.otohns.2007.08.008. [PubMed: 18036412].

62. Rapp SJ, Pan BS, Schwentker AR, Van Aalst J. Effects of Autologous Fat and ASCs on Swine Hypertrophic Burn Scars: A Multimodal Quantitative Analysis. Plastic Reconstruct Surg Glob Open. 2017;5(11). 